\title{
Enhancing graduates' enterprise capabilities through work-integrated learning in co-working spaces
}

\author{
Denise Jackson ${ }^{1}$ (D) $\cdot$ Hairong Shan ${ }^{1}$ (D) $\cdot$ Stephanie Meek ${ }^{1}$ (D)
}

Accepted: 19 August 2021 / Published online: 6 September 2021

(C) The Author(s), under exclusive licence to Springer Nature B.V. 2021

\begin{abstract}
Complex and rapidly evolving work contexts augment industry calls for future-capable graduates that can demonstrate enterprise capabilities such as critical thinking, problemsolving, collaboration, and value creation. Gaps between employers' expectations and evaluations of higher education (HE) graduates' enterprise capabilities continue to drive university curriculum renewal. There is a particular focus on work-integrated learning (WIL), a spectrum of industry-student engagement activities which provide valuable opportunities for developing and applying skills and knowledge, including enterprise capabilities. Despite small-to-medium enterprises (SMEs) offering fertile ground for enterprise learning, challenges limit their engagement in workplace-based WIL (internships/placements) due to resource and supervisory constraints. This study explores how co-working spaces may support SME engagement in WIL to develop enterprise capabilities, better preparing HE students for future work. It piloted two rounds of business student internships in the largest co-working space in Western Australia, surveying and interviewing both students and workplace supervisors to gauge development and understand enablers and challenges during WIL. Findings affirmed the synergistic value of SMEs and co-working spaces for fostering students' enterprise capabilities, particularly communication and critical thinking skills, innovative behaviour, and building confidence. While some of the challenges which impact on SMEs engagement and outcomes in WIL remained, the co-working environment offered unique exposure to entrepreneurial mindsets and rich opportunities for collaboration, networking, and formal training. This study offers important insights on WIL design that increases participation among SMEs, a targeted objective of Australia's national WIL strategy, and leverages co-working space environments to produce future-capable graduates.
\end{abstract}

Keywords Work-integrated learning · Enterprise capabilities · Future work · Graduate · Industryeducation collaboration $\cdot$ Co-working space

Denise Jackson

d.jackson@ecu.edu.au

1 School of Business and Law, Edith Cowan University, 270 Joondalup Drive, Joondalup, WA 6027, Australia 


\section{Enhancing graduates' enterprise capabilities through work-integrated learning in co-working spaces}

Disruptive technology and globalisation have led to rapidly changing work contexts (World Economic Forum 2020), increasingly characterised by gig arrangements, remote and flexible working, and interactive open spaces (Cascio 2019; Khazanchi et al. 2018). Workers, including students transitioning from higher education (HE), therefore need to engage in lifelong learning (Sony and Naik 2019), be agile, collaborative, have an enterprising mindset, and be able to transfer skills across different contexts (Bridgstock 2019). Enterprise capabilities are widely recognised as critical for graduates' effective transition to work, spanning critical thinking, creativity, problem-solving, digital literacy, ethical behaviour, teamwork, and networking skills (Bacigalupo et al. 2016; Milligan et al. 2020). Collectively, these support the creation of one's own opportunities and advancing knowledge and enacting change across different industries (Hajkowicz et al. 2016).

The value of education-industry collaboration in developing enterprise capabilities is widely acknowledged (Clarke 2017; Sin and Neave 2016). A plethora of entrepreneurialrelated initiatives have emerged, including incubators/start-ups and hackathons (Kay et al. 2018). When embedded in HE curriculum, these form Work-Integrated Learning (WIL) activities where students engage with industry/community partners through authentic learning and assessment (Jackson 2018), encompassing workplace-based activities (internships/placements/practicums), and virtual/on-campus offerings (project-based learning/consulting/simulations). Micro- and small organisations offer particularly fertile learning ground for student development of enterprise capabilities during WIL, given their focus on ideation and innovation (Kay et al. 2018)

However, there are barriers to students' leveraging the benefits of WIL in smaller businesses. First, smaller businesses are often prevented from engaging in WIL due to supervisory and resource constraints (Department of Industry 2014). Second, not all students can participate in WIL due to personal circumstances or it not being offered in their discipline (Universities Australia 2019). The need to engage more smaller businesses in WIL is recognised nationally (Universities Australia et al. 2015) and may be critical to easing documented skill gaps in certain graduate enterprise capabilities, particularly problem-solving, digital literacy, communication, and collaboration skills (Hurrell 2016; National Association of Colleges and Employers 2018). The recent linking of Australian HE funding to industry engagement (Australian Government 2020) may increase student participation in WIL, although not necessarily in smaller businesses.

Increasingly, smaller businesses are choosing to operate in co-working spaces, forming the highest proportion of co-working space members (Office Hub 2019). More than a physical open space, co-working spaces are "flexible, shared, rentable and community-oriented workspaces occupied by professionals from diverse sectors", which are intentionally "designed to encourage collaboration, creativity, idea sharing, networking, socialising and generating new business opportunities" (Fuzi 2015, 462). Despite the combination of smaller organisations in co-working spaces potentially offering significant opportunity for enterprise capability development, there is little research on WIL in this context. Therefore, we sought to explore how co-working space characteristics influenced students' enterprise capability development and whether they supplanted the observed challenges of WIL in smaller businesses. We piloted and evaluated HE student internships within micro/small businesses based in an 
Australian co-working space, seeking ways to overcome known barriers to smaller business' participation in WIL.

We used a multi-stakeholder and mixed-method design to: (i) examine the extent to which interns develop enterprise capabilities in a co-working space; (ii) explore how interns developed enterprise capabilities in a co-working space; and (iii) identify any challenges or enablers to enterprise capability development during WIL. This paper reviews related literature, outlines methodology, and then presents results. Implications and stakeholder strategies are discussed, followed by concluding remarks.

\section{Background}

\section{Labour market demands of new workers}

Enterprise capabilities may be considered a subset of a broader suite of generic graduate capabilities, the latter often captured in institutional, national, or international frameworks (for example, OECD, 2014). Recent literature linking contemporary work and skill demands highlights enterprise capabilities' pervasive nature, and Bowles et al. (2019) assert that frameworks of enterprise capabilities and employability/professional/core/soft skills are measuring the same thing: core competencies for future work and life success. Enterprise capabilities are predicted to become more important (Foundation for Young Australians [FYA] 2016a), given employers are increasingly seeking workers who add value in diverse work contexts defined by Industry 4.0 (Deloitte 2019).

Extant literature characterises enterprise capabilities as encompassing adaptability, communication, and collaboration (Australian Industry Group 2016), a mindset that embraces change and innovation (FYA 2016b), the ability to network (Bridgstock 2019), commitment to work and stress tolerance (Succi and Canovi 2019), curiosity, creativity, and problem-solving (Howard 2016), digital literacy, and critical thinking and judgement (Lydon et al. 2014). Enterprise capabilities are transferable across contexts and are defined by personal agency, enthusiasm for lifelong learning, and global citizenship (FYA, 2015). Collectively, they enable graduates to fulfil their expected role as confident, reflective practitioners (Jackson 2016) who can respond to challenges across contexts and identify, evaluate, and enact opportunities for change (Bacigalupo et al. 2016; Rae 2007). Also important are new graduates' ability to effectively perform across diverse professional settings (Howard 2016; Milligan et al. 2020) and be able to generate opportunities and employment (Hajkowicz et al. 2016).

\section{Value of WIL for developing enterprise capabilities}

WIL can be valuable for developing enterprise capabilities (Australian Council of Learned Academies 2016). Smith et al.'s (2019) national review of learning and assessment strategies for developing and evidencing enterprise capabilities affirms the importance of various types of WIL. Workplace-based internships can help students to understand enterprise capabilities' meaning and purpose, and how they are used in different contexts (Jackson 2015). Industrystudent mentoring programs foster a collaborative mindset and improve mentees' interactions with established professionals (Mahlberg and Riemer 2017). Jackson and Bridgstock (2020) found in-curricular incubator/start-up activities important for learning new skills, gaining 
relevant experience, broadening networks, and creating employment compared with other forms of WIL.

Despite reasonably strong HE student participation in WIL in Australia, barriers exist to widespread implementation in non-accredited disciplines where WIL is often not mandatory, such as Business/Commerce (Universities Australia 2019). This is particularly so for workplace-based experiences in smaller organisations where fewer staff members are available with sufficient expertise and time to provide guidance, mentorship, and feedback to interns (Jackson et al. 2017). Having the required insurances, policies and procedures, and suitable desk space/equipment are further barriers to smaller organisations participating in workplacebased WIL (Department of Industry 2014). International students often favour internships in larger, prestigious organisations (Gribble 2014), and students may associate smaller organisations with lesser networking and employment opportunities. Collectively, these factors may inhibit micro/small businesses from leveraging the benefits of WIL, such as staff development in mentoring/supervision, and identifying future graduate talent.

\section{WIL in co-working spaces}

Co-working spaces are where entrepreneurs, freelancers, and professionals - from start-ups to large businesses - share a physical space, facilities, and resources while operating their own businesses independently. They provide workplace flexibility (Kropp 2019) and allow people to connect and collaborate using common spaces (kitchens/event venues/meeting rooms) to develop a sense of belonging (Bouncken and Reuschl 2018). Their use has grown worldwide due to increased numbers of freelancers/start-ups/micro-businesses, creating a need for workspaces with lower rents, flexible leasing terms, and a shared environment for networking, collaboration, and innovation (Clifton et al. 2019). The 309 Australian co-working spaces (Property Council of Australia 2018) are expected to exceed 25,000 by 2022 (Coworking Resources 2019), although COVID-19 may reduce this forecast given the challenge of restrictions in shared facilities.

Co-working spaces have evolved into multiple forms, distinguished by membership types, infrastructure/facilities, and size (Bouncken and Reuschl 2018). Ownership influences their purpose with not-for-profit organisations' spaces focused largely on social enterprise, large organisations' (e.g., Apple) on flexible and innovative work cultures, government-funded on improving local employment and knowledge exchange, and universities' on enhancing student learning and research innovation (Mahlberg and Riemer 2017). The co-working space embodies entrepreneurship, cutting-edge technologies, and transdisciplinary and collaborative working (Mahlberg and Riemer 2017), offering valuable opportunities for building networks and developing enterprise capabilities. HE student internships in co-working spaces could bridge skill gaps in enterprise capabilities and better prepare them for Industry 4.0. Co-working spaces could support universities by potentially matching students with co-working members and giving interns access to developmental activities (Fishburners 2020).

\section{Methodology}

The study adopted a mixed-methods design and was exploratory in nature. We do not hypothesise the specific impact of internships on certain capabilities, given the paucity of 
earlier work in this area. The study draws on a small sample yet produces rich data to address the three research objectives.

\section{Participants}

Table 1 summarises the student and host organisation characteristics for the 11 internships in the largest co-working space in Western Australia. All interns were placed in micro $(<10$ employees) or small (10-49 employees) (OECD, 2021) private businesses from various industries. The high proportion of Professional Service businesses reflects the distribution across co-working spaces nationally (Office Hub 2019).

\section{Procedures}

Business students from a Western Australian university undertook an internship in separate small or micro-businesses based in the same co-working space. There were two rounds of internships, July-November 2019 and February-June 2020. In each round, one intern was hosted directly by the small business managing the co-working community. Based in the central business district within the capital city, the co-working space - typical of others-has numerous membership options, shared facilities, and weekly community events/workshops to connect co-workers and businesses. The internships involved 100-150 h in the workplace, typically structured as $1 / 2$ days per week over 13 weeks. They focused on students' application of theoretical knowledge and skills learned during their degree. Most second-round internships adopted a "hybrid" format, combining face-to-face with virtual working. The transition to virtual arrangements part-way through the internship was prompted by COVID-19 restrictions yet reflects growing acceptance of the value of virtual WIL (see Winchester-Seeto and Piggott 2020). These interns completed tasks remotely and connected with host organisations via phone/email/teleconferencing and/or collaborative working tools.

As part of the internship, students completed two online surveys, self-assessing their enterprise capabilities before and after WIL. Each host organisation assigned one workplace

Table 1 Summary of student and host organisation characteristics

\begin{tabular}{llll}
\hline Variable & Group & $\mathbf{N}$ & $\%$ \\
\hline \multirow{2}{*}{ Gender } & Male & 3 & 27 \\
& Female & 8 & 73 \\
Sector & Private & 11 & 100 \\
& Not-for-profit & 0 & 0 \\
Industry & Public & 0 & 0 \\
& Finance/insurance/property/business services & 7 & 64 \\
& Manufacturing/wholesale/transport/storage/logistics & 0 & 0 \\
& Electricity/gas/water/agriculture/forestry/fishing & 1 & 9 \\
& Mining/construction & 1 & 9 \\
& Health/community/public, cultural, recreational services & 0 & 0 \\
& Personal services/retail/accommodation/cafes/restaurants & 0 & 0 \\
& Communications & 2 & 18 \\
Organisation size & Education & 0 & 0 \\
& Micro (less than 10 employees) & 3 & 27 \\
& Small (10-49 employees) & 8 & 73 \\
& Medium (50-149 employees) & 0 & 0 \\
& Large (150+ employees) & 0 & 0 \\
\hline
\end{tabular}


supervisor who evaluated their intern's enterprise capabilities through an online survey at the conclusion of the internship, contributing towards the students' final assessment. Both students and supervisors could opt out from sharing their data for research purposes. Interns and supervisors were also invited by email to attend an individual, semi-structured interview (virtual or face-to-face) after the internships.

\section{Measures}

Our study did not intend to propose a new set of enterprise capabilities and drew on Jackson et al.'s (2020) evidence-based framework which captures 10 future-oriented capabilities and 45 constituent behaviours desired of new graduates when transitioning to work. Developed in partnership with industry, it encompasses enterprise capabilities identified in the literature. An earlier version has been used extensively to gauge capabilities and their development during WIL (for example, Jackson 2015). Interns completed pre-WIL and post-WIL self-assessments of their capabilities, rating themselves on each behaviour (five-point Likert scale from "needs improvement" [1] to "high ability" [5]) to evaluate learning gain for the first research objective. Supervisors assessed whether their intern had demonstrated each behaviour during WIL to the minimum standard expected of a graduating student (yes/no/NA). "NA" indicated the intern was not given the opportunity to demonstrate a particular behaviour. Qualitative data were used to address the second and third research objectives. Interns and supervisors were asked during their interviews: (a) how each of the enterprise capabilities was developed during the internships, and (b) any challenges or enablers that supported or hindered capability development.

\section{Analysis}

Survey data were analysed using SPSS 24.0. To gauge capability development, the interns' mean ratings were computed pre-WIL and post-WIL and any improvement (or decline) evaluated using paired sample $t$-tests $(\alpha=.10)$. Normality plots and measures of skewness and kurtosis being within their respective limits of 3 and 10 (Kline 1998) indicated the distribution of variables was approximately normal and that $t$-tests were viable. The proportion of supervisors stating their intern had demonstrated capabilities to a graduate standard was evaluated. Interviews were transcribed and thematically analysed. Widely used in qualitative research (Thomas 2006), student and supervisor interview responses were inductively coded at individual response level for the posed questions. Analysis of interview data produced frameworks of themes for, first, what supported enterprise capability development in the micro/small business and/or co-working environment, and second, challenges and enablers for capability development. Identified themes were discussed to ensure consensus and enhance validity, following Merriam's (1995) recommended practices for qualitative research. Quotes from supervisors in micro-businesses are denoted by $\mathrm{M}$, in small businesses by $\mathrm{S}$, and interns by $\mathrm{I}$.

\section{Findings}

Survey rating data on the development of each capability between pre-WIL and post-WIL assessments are first presented, addressing the first research objective. Drawing on 
interview data, these are followed by student and supervisor perceptions on how capabilities were developed (research objective two) and challenges to development (research objective three).

\section{Extent of capability development}

Table 2 summarises students' means and standard deviations for each behaviour before and after WIL. Broadly, students perceived they were proficient across all 10 capabilities, average ratings approaching or exceeding four both pre/post-WIL. The "improve" column notes the difference between pre-WIL and post-WIL assessments. Paired sample $t$-tests $(\alpha=.10)$ highlighted mean ratings that changed significantly during WIL (emboldened and asterisked in Table 2), with respective $t$ and $p$ values shown in the same cell. Results showed significant learning gain in different aspects of communicating effectively: giving and receiving feedback ("seek, give, and receive feedback appropriately and constructively"), non-verbal communication ("recognise and respond appropriately to non-verbal cues"), and written communication ("communicate in a clear, structured, and professional manner using written formats most appropriate for the target audience"). There was also significant improvement in critical thinking: conceptualisation ("recognise and interpret patterns and concepts in documents and scenarios to understand the 'bigger' picture") and evaluation ("objectively analyse and make judgements on key points in a range of documents and scenarios"). Significant positive effects were reported for innovation ("initiate and support change and add value by embracing new ideas and showing ingenuity and creativity in addressing challenges and problems"), self-efficacy ("be self-confident in dealing with the challenges that employment and life present"), and work/life balance ("ability to maintain well-being and a productive balance of work and life"). Interestingly, a significant negative mean change was reported for reasoning, an aspect of problemsolving, and drive, within professionalism.

Remarkably, a negative number was recorded for cultural/diversity awareness ("work proactively and appropriately with people from diverse groups"), reasoning ("use rational and logical reasoning to deduce appropriate and well-reasoned conclusions"), initiative ("take action unprompted to achieve agreed goals"), analysing/diagnosing ("analyse facts and circumstances and ask the right questions to diagnose problems"), adaptability ("adaptable to change and demonstrates flexibility in approach to all aspects of work"), commercial awareness ("recognise different organisational structures, industries, and sectors and the importance of adapting behaviour and attitudes to varying missions, operations, culture, policies, and systems"), time management ("manage one's own time effectively to accomplish goals"), relationship building ("able to initiate and engage in appropriate conversation, build networks, and differentiate between personal friendships and collegial relationships"), drive ("go beyond the call of duty by pitching in, including undertaking menial tasks, as required by the business"), and goal and task management ("set, maintain, and consistently act upon achievable goals, prioritised tasks, plans, and schedules").

Supervisor assessments were largely positive for interns' demonstration of behaviours to graduate standard during WIL. However, concerning results were reported for conflict resolution ("address contentious issues and matters of conflict with key stakeholders in a constructive and appropriate manner"), numeracy ("read and analyse numerical data and apply it to a given context"), using data ("be able to interpret data and use it in an informed way"), and 


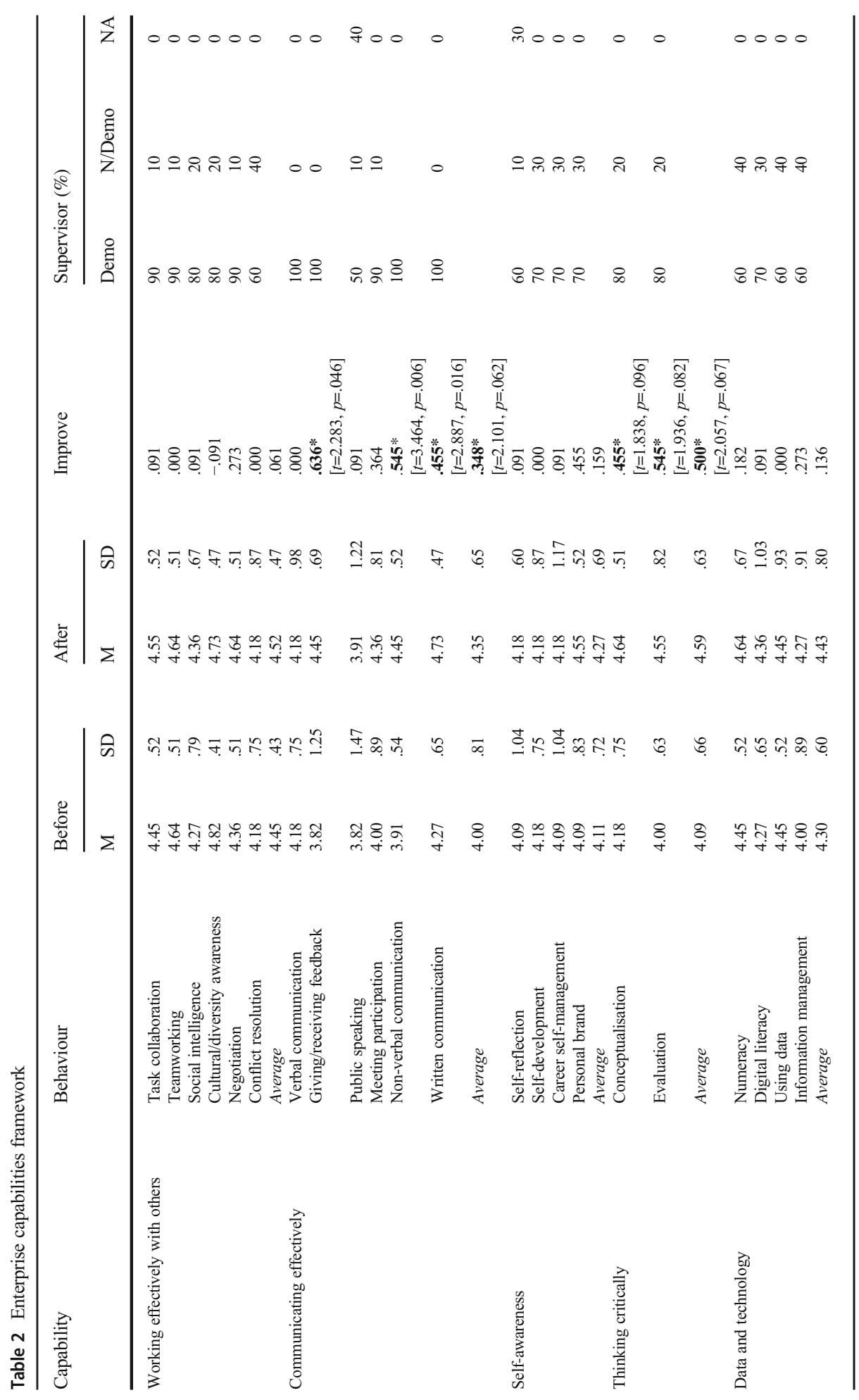

\section{글 Springer}




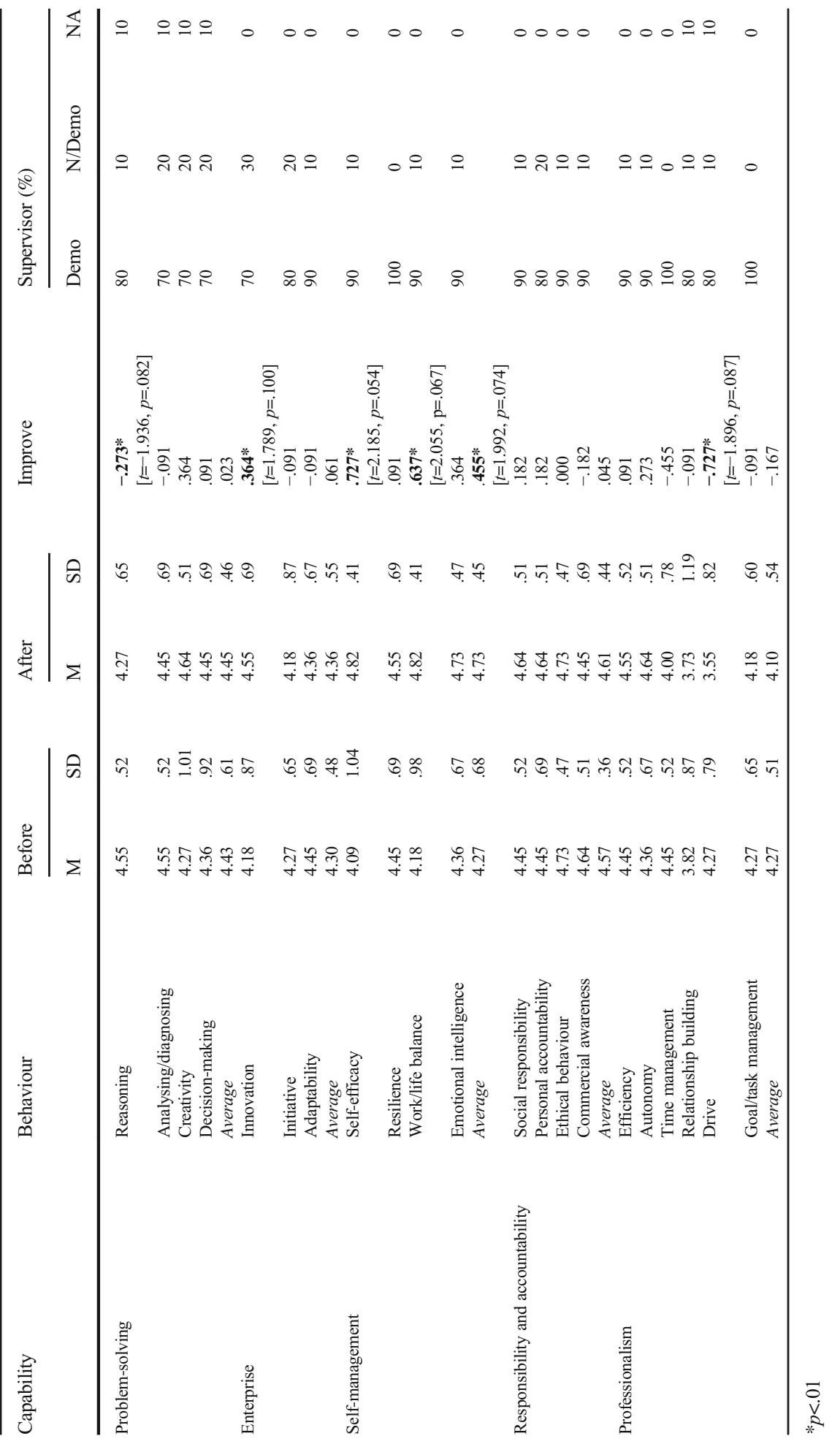


information management ("retrieve, interpret, evaluate, and appropriately use information in a range of digital and analogue formats"), with $40 \%$ not demonstrating to graduate standards during WIL. There were limited opportunities to demonstrate public speaking and selfreflection.

\section{Factors that support enterprise capability development}

During the interviews, interns and workplace supervisors identified five key factors that support capability development among interns in micro/small businesses within co-working spaces.

\section{Organisational culture}

Several supervisors highlighted the importance of a supportive, positive organisational culture for fostering confidence and capability among interns who are often afraid of expressing themselves and making mistakes. They felt the intimacy of small/micro-organisations affords trust, openness, and transparency, creating a culture of exchange, sharing, and discussion. One observed, "We create the safe space so they can think critically, problem-solve, and take the initiative to go and do it by themselves. We provide continuous guidance in terms of what are they doing, what they need to do and the tools to improve" (S7). This collaborative support extended to developmental strategies to achieve career goals, "We ask team members to share professional development plans where you talk about your ambitions and development opportunities. Sometimes people are afraid to share but we need to be aware of what the other is doing, what the other wants, so we can, as a team, help each other. The intern was part of that dynamic" (M1). Interns affirmed how the intimate, supportive work culture encouraged them to trust others and feel comfortable and confident to share their views. For example, "They always wanted me to contribute and always appreciated my feedback, so I slowly built my confidence. By the end of it, I felt more comfortable in raising questions, or if I felt there was a better way, I was more open, and more confident to speak out about it." (I5). Another stated, "My fellow co-workers make you feel like you're contributing. I didn't feel left out. They didn't make me feel like I don't know anything, so that was really good for me" (I11).

Supervisors found small business' culture of autonomy, sharing responsibility, and selfmanagement encouraged interns to identify and solve problems themselves and create value for the business. One intern commented, "Working proactively is something that I learnt a lot about, like being able to set myself task. Certainly, you can't just jump into some random thing, you have to figure out whether it's going to be useful and where the value adds to the company" (I5). One supervisor observed how the co-working space extends the positive aspects of individual businesses' cultures, "serving as a reflection of the organisation's culture, specifically in relation to how staff are expected to engage, self-manage and perform." (M3).

\section{Co-working space environment}

The co-working space environment itself was considered to support skill development. Interns felt it built their commercial awareness, exposing them to different organisations and roles, significant amounts of data and information, and up-to-date knowledge of various industries. Supervisors believed the high-tech environment increased interns' awareness of the role and importance of technology-related skills and technologies used in different industries, including 
cutting-edge software and systems. It also provided key insights into professional conduct, aiding interns to "build a certain degree of professional communication" (I7) and "adopt the mannerisms people use and the actions people do" (I1) through observation and interaction.

The proximity of micro/small businesses encouraged interaction, reciprocity, and knowledge sharing among workers. Common-use areas gave interns the opportunity to informally network and just simply "being around people" (I1) from diverse businesses provided interns with rich insights on collaboration, ideation, and value creation. One intern commented, "The major benefit (of co-working spaces) is the ability to very quickly recognise other people with very different sets of talents and how that would result in business opportunities and joint ventures" (I7), "It's quite eye opening that you are exposed to new ideas, and new things that you wouldn't normally know" (I5) and "Once you're in a coworking space, the possibilities and opportunities are endless" (I11). Supervisors described interns as "being in one big networking session, all the time." (S1). The open and informal structures helped to foster an entrepreneurial mindset, "You get used to constantly thinking outside-the-box so you can collaborate with the person next to you. It shapes the way that you work." (S9).

Some felt the space propelled students' entrepreneurial intention for future career, "It is such a productive space in a way which I haven't really experienced before. People are there to work and they want to work. I always thought of entrepreneurship but being in a space where there are so many around just makes it all more achievable. I got the feeling that I could realistically do something and there's support around you as well' (I1). The space' culture also fostered lifelong learning, for those proactive in leveraging what was on offer. One supervisor commented, "Co-working spaces focus on learning how to learn, putting the responsibility back on the individual to take initiative with the provided resources and opportunities for networking, training events, and support services" (S9).

\section{Supervisor support}

Supervisor support in a business with few employees was recognised as critical by all interns. They appreciated supervisors who were inspiring, keen to teach, gave constructive feedback, and provided opportunities to learn. For example, "My supervisor has been really supportive and is always filling me in. I'm more confident in myself having to adapt. I look up to her, I have learnt so much from her." (I11). The small organisation size enabled some interns to collaborate with their supervisors on tasks, which they found particularly useful, "Through discussing tasks with my supervisor, I learnt that the way I am thinking isn't necessarily the way that other people think" (I7). All supervisors recognised the value of on-the-job training and shadowing for developing their interns' capabilities.

Although all supervisors guided and supported their students during WIL, their styles varied. Some were warm and supportive, "Taking the intern under my wing to train them into a way of thinking" (S8), which interns appreciated, "I think openness and willingness to meet me where my understanding was is very important" (I7). Another commented, "My supervisor is very down-to-earth and willing to help, and I think that's incredibly important in any kind of teaching position" (I7). Other supervisors encouraged interns to be independent and quick learners, issuing tasks with a "sink or swim" attitude. One asserted, "It's better for them to get the idea of how the day-to-day runs" (S5).

Some supervisors were not used to providing continuous feedback to staff and welcomed interns who were "able to move and then go back and kind of iterate, and not just get stuck because they don't have specific feedback around something” (M1). Notably, some 
supervisors felt certain capabilities were a function of experience and/or personality and considered aspects of "professionalism" foundational to any job, "People will struggle with getting jobs in professional industries if they don't already have that skill” (S1).

Given the need for accountability and learning quickly in smaller businesses, supervisors highlighted the importance of interns reflecting on their performance and identifying ways to improve, particularly for self-awareness, self-management, problem-solving, and data and technology. Comments emphasised that while businesses can facilitate capability development, personal agency in self-reflection and engaging with constructive feedback is critical. For example, "What I'd like to see from any student/graduate is a level of ownership, to be able to ask themselves at the end of any task how could this have been done better. Given that they're in a period of significant learning, those things are really core to be able to solidify knowledge and to be able to grow fast" (S6). Some supervisors facilitated reflection, for example "I always set up the interns' goals for the day and revisit those with the student to make sure that reflection is there" (S8), while others expected students to do it on their own. Although several interns saw the value of self-reflection, engagement in reflective practice varied. The reflective activities embedded in the academic component of the WIL program were sometimes separated from their workplace experience, for example "I need to take time to reflect on myself. It's not something that I was exposed to during WIL" (I10).

\section{Formal training}

All interns were formally onboarded into the space by co-working staff, including a physical tour and introduction to systems and community events. Interns also participated in inductions with their hosts who explained core business, relevant systems, staff roles, feedback mechanisms, and expectations on workplace performance and behaviour. Supervisors considered inductions important, "to network and allow them to know who is doing what in the company and reach out whenever possible for working and communicating effectively" (S7). Interns also found them useful, "I know organisational structure, who's doing what, it's all pretty informative" (I4), and "Although the first day was super overwhelming, I got introduced to so many new tools and programs, I learnt a lot from that" (I6).

The co-working space enabled interns in both rounds to participate in numerous face-toface and virtual training activities, such as workshops/seminars on design thinking, digital literacy (AI/machine learning), and giving pitches. Interns also participated in at least two formal networking events held by the community (e.g., breakfasts/lunches/sundowners), often attending events together, the reciprocal support easing feelings of being overwhelmed. These events/activities gave them the opportunity to expand their networks and connect with other entrepreneurs sharing the co-working space. Second-round interns attended face-to-face networking sessions prior to transitioning to remote working and then engaged in virtual networking events, such as virtual morning meetups and business idea pitches. While supervisors encouraged their interns to participate in the space's formal training, it often focused on technical skills (e.g., technology-related), whereas softer capabilities (e.g., teamwork and networking) were expected to be developed through the co-working and micro/small business experience. 


\section{Task processes}

Working in a micro/small business environment exposed interns to many areas of the business, providing them with meaningful exposure to varied tasks. One commented, "In a small business I get to be involved in the process of planning and operations, working closely with the founders and directors. That's really good because you can observe so much. It takes a while until you realise how much you learn from it" (I6). The co-working space created an energy of productivity and entrepreneurial spirit, motivating interns to complete tasks in a timelier manner. Micro/small organisations need students to fit in and produce meaningful work quickly. Being given practical, challenging, outcome-oriented tasks with a clear understanding of their purpose encouraged the development of working effectively with others, thinking critically, and being creative, along with improving autonomy. Directing interns to background reading to unpack particular concepts was considered helpful by interns, "Giving me time to prepare for tasks was great. I learnt a lot from that. It was a really big challenge because there were so many components, but I am much more comfortable now" (I6).

Collaboration in approaching and completing tasks was encouraged through regular meetups, brainstorm/reflection sessions, planning/management meetings, and debriefs, "Our daily morning stand-ups really stood out, talking about our plans for the day, sharing what we were meant to do, finding solutions to someone's problem or motivating each other by giving feedback. Different ideas coming together to create the greater good" (I9). Collaborating enhanced communication skills, accountability and responsibility, and professionalism, "We have Google Docs that we share and work on at the same time, so what I put in there they must be able to understand, and it is important to maintain professionalism at all times" (I6).

\section{Challenges with capability development}

Interview data highlighted several challenges with interns' development of enterprise capabilities in micro/small businesses within the co-working environment. These related to internship design, supervision, and intern capabilities.

\section{Internship design}

Several supervisors noted that smaller businesses need to be agile, continually reviewing and adjusting their focus and producing work at a fast pace. Some found this created difficulties with consistently aligning tasks to their intern's initial learning plan. One commented, "It was very important for me to set a specific project from the get-go, but it changed as we went, because we change things so quickly here" (S1). Further, the 13-week internship length limited the scope and depth of assigned tasks for some interns, impacting on their ability to independently perform significant work that drew on theoretical knowledge. Some supervisors felt the internship gave students exposure to contemporary working conditions rather than the clearly defined development pathways akin to graduate positions. One described the learning cycle as "The first time I hold your hand, the second time you're going to do it by yourself asking what needs to be done, by the third time you can do it alone. This doesn't happen when you have only three-month internships, so we end up just giving them smaller tasks instead of full packages of work, so I believe it's less critical thinking, less initiative" (S7). 


\section{Constraints on supervision}

Constraints on supervisor time were common, impacting on their ability to support interns, "Capacity was an inhibitor and I think you will find that with a lot of small businesses, I wasn't in sight all the time" (S1) and "I felt a little badly for the intern. I have been very busy" (S5). The resultant lack of guidance and feedback was problematic for some interns, "To be honest, it was more like me doing these things and not knowing if it was good" (I3) and "I understand (supervisors) do have a lot of things to do but I'm an intern, I don't know if everything I'm doing is being done the way it's meant to" (I9). While supervisor feedback was inherent to students' learning, with progress updates required by academic coordinators and a formal evaluation at the conclusion of the internship, the provision of ongoing feedback varied with supervisor schedules and capacity.

Some interns felt their supervisor adopted a "sink or swim" approach due to their own autonomous learning style and time and resource pressures. This meant less guidance and feedback, creating pressure which was intimidating and unhelpful. For example, "He really tried to break me if that makes sense, and he did because I started to cry at the end of the day. He wants me to grow, but at that point in time when it was so new for me, I didn't like it at all." (I6). Interviews highlighted the varying levels of supervisor experience in supporting interns, ranging from formal mentoring experience in larger organisations to young entrepreneurs reliant on the internship to develop their mentoring skills.

\section{Intern capabilities}

Several supervisors felt interns were unprepared for the fast-paced work, and their skills, particularly social and discipline-based, did not meet expectations. Having to upskill students during the internship was considered costly as it detracted from core business, "Not many university students are job-ready. They suffer a great shock when they get told 'have this done in two hours please' and they say, 'but I usually get three weeks"' (M4). Another stated, "A lot of what they delivered was not the quality we expected; we didn't have the time to help them get to the point that they needed. We work at a very fast pace, so we just had to do it ourselves. They still have the opportunity to see how it needs to be done but we don't really have the time to train the students properly." (S7).

Interns themselves noted how low confidence, attributed to limited work experience and industry knowledge, hindered their capability development, "I struggle with putting myself out there and asking questions. I lack confidence to chase up and ask if I have done things right" (I2), "I wasn't confident talking with people of different seniority levels" (I5), and "Most of the time I'd be quiet because I felt like I might say the wrong thing, or it might be out of context" (I9). This meant interns often struggled to engage with others outside their organisations and leverage networking opportunities in the co-working space, "I'm only a university student and I can't really compete in a conversation to a professional level yet" (I1). Interns felt most conversations did not add much value to their knowledge, stimulate creative ideas or contribute to their network, although some observed an improvement in self-introductions over time. One supervisor also noted the limitations on networking in the co-working space, "I think it is a little over-played. Depending on how you are engaged, you'll have the opportunity to grow that inner circle, but it's not like I'm going to interact with a hundred different people on a weekly basis" (S6). 
Some supervisors questioned students' engagement with the internships, noting a lack of research and understanding of their host's business prior to commencement. Not all attended available training or events in the co-working space, which interns attributed to external commitments (paid work/study/caring/social) while supervisors felt internship hours did not coincide with events or interns were unaware of what was scheduled. Further, the co-working space manager/intern supervisor recognised that some of the space's training was industryspecific and/or on topics beyond students' level of understanding, noting challenges with orienting events for interns/less experienced workers.

Notably, the shift in the second round to remote working produced mixed effects for enterprise capability development. As most allocated work was cloud-based, the disruption to completing tasks appeared minimal, and regular, virtual check-ins/debriefs/meetings provided the necessary support and guidance. Both interns and supervisors observed how remote working allowed for greater discussion of assigned tasks, the "no-conversation rule" in shared working spaces often inhibiting clarification and questions. One supervisor commented, "A coworking space can be very individualistic because there are implicit rules about not talking loudly and keeping conversations to a minimum. It constrains development if you're someone that actually needs to discuss stuff to actually understand" (M3). Some interns felt that remote working encouraged autonomy, improved their self-management, and helped them to learn new communication tools. Some, however, noted they were less able to freely network, and the more structured virtual events (with assigned break-out rooms) inhibited developing personal connections.

\section{Discussion and implications}

Findings indicated that internships in micro/small businesses based in co-working spaces contributed to developing students' confidence, feelings of "making a difference", and most enterprise capabilities. Learning gains, and how they were achieved, support literature on the positive impact of WIL. Capabilities that were less successfully developed broadly align with documented graduate skill deficits. Clearly, smaller businesses offer a supportive and positive learning environment and are less constrained by hierarchical structures and processes. Challenges reported during the internship, however, resonate with earlier work and suggest that despite the value-add of the co-working environment, it does not supplant obstacles to WIL in smaller businesses.

Specifically, the environment enabled communication skills to flourish, important given their criticality for contemporary work which is often defined by horizontal structures and realtime communication with diverse stakeholders on multiple platforms (Clifton et al. 2019). Learning gains in critical thinking are welcomed, given graduate skill deficits and their importance for future work (Chikeleze et al. 2018; Pennington and Stanford 2019). The coworking space also gave rich insights into embracing change and different forms of creativity, ideation, and value creation, vital for innovation and organisational success in highly competitive markets.

The positive effects on confidence will help students to collaborate, network, and successfully apply their theoretical knowledge in diverse contexts, supporting their transition into future leadership (Chikeleze et al. 2018). The steep learning curve in managing work-life balance during WIL supports earlier studies (Jackson 2015; Jackson et al. 2017), the instilling of effective strategies important for well-being and managing increasingly unclear boundaries between work and home (Succi and Canovi 2019). 
We believe the lower mean ratings after WIL do not reflect measurement issues but instead the Dunning-Kruger effect (Kruger \& Dunning, 1999), a form of bias where less competent individuals overestimate their capabilities. Here, students with limited prior work experience "do not know what they don't know", overestimating their capabilities until they are exposed to industry standards during WIL (see Smith et al. 2014). They could also be attributed to a loss of confidence during the internship period. One student noted, "I think I had inflated confidence prior to starting. Where I started from must have been worse than I had assumed" (I7). Accordingly, the significant, negative change in reasoning and drive was not reinforced by supervisors who felt most interns were performing to graduate standard. Effectively coordinating multiple university assignments and external commitments may have led to earlier positive ratings for time management and goal/task management yet the challenging, fast-paced start-up context later led to lower ratings.

While one might not expect mastery to graduate level for conflict resolution, supervisors' relatively poor evaluations for numeracy, analysing, and using data and information align with reported skill deficits (Deloitte 2019), disappointing given their criticality in contemporary work (Pennington and Stanford 2019). Perhaps interns did not engage with relevant training, the learning curve was simply too steep in this area, and/or supervisor/co-workers' may have lacked time to support developing these capabilities. The lack of self-reflection in the workplace is concerning, given its pivotal role in connecting theory and practice during WIL (Tynjälä et al. 2003). Reflective activities/assessments endemic to WIL, such as learning journals, could be more explicitly interwoven into work practices, rather than as separate academic tasks.

Interns in micro/small businesses appeared more likely to get involved in a wide range of tasks, observing diverse practice and "getting their hands dirty" applying theoretical knowledge. WIL design, however, needs to allow for fluidity in assigned tasks due to businesses' changing needs and circumstances, a single project for the entire experience not always appropriate. Actively reflecting on initial learning goals with one's supervisor, and how this was adapted and why, could prove valuable. While the all-important positive work culture that encourages curiosity and confidence may not be ingrained in all community businesses, coworking spaces' dynamic, fast-paced, and forward-thinking cultures (Clifton et al. 2019) appeared to support this. Further, given the collective focus on enterprise and entrepreneurship, many internships exposed students to dynamic, self-managed cultures that encourage autonomy, problem-solving, and a value-adding mindset. The environment also appeared to increase entrepreneurial intention among the interns.

In line with good WIL practice, inductions by the community and hosts were critical (Edwards et al. 2015). The co-working space's formal training extended small businesses' own offerings, upskilling, and instilling the importance of independent and lifelong learning. Embedding student participation in community's formal training into WIL design, particularly in technology-related topics, may increase engagement. Inspiring interns to share their acquired technological knowledge and utilise it in workplace tasks could further optimise benefits. Encouraging students to seek feedback and opportunities for learning was illuminated, resonating with others' illumination of agency in optimising WIL experiences (for example, Billett 2011).

Industry calls for lengthening internships echo earlier studies (for example, Jackson et al. 2017). Extending or delivering them intensively may afford more substantial tasks and structured learning pathways which explicitly target certain enterprise capabilities. The "hybrid" internship highlighted benefits specific to both face-to-face and virtual modes. Virtual 
internships' affordance of discussion and questions unconstrained by the space's noise regulations is important for learning. They also allow greater flexibility in scheduling tasks to achieve work-life balance, participation in virtual community events/training, and improved access to WIL for some students. Observed difficulties in networking highlight the need for stakeholders to think creatively about ways to create and sustain connectedness in online environments (Bridgstock and Tippett 2019).

Although co-working provides valuable opportunities for informal/formal networking for skill development and career progression, there were clear messages that stakeholders need to initially build interns' confidence so they can effectively engage with community members. Incorporating team-building activities, speed-dating networking events during induction (interns engaging with community businesses in rotation), or co-worker buddy-systems for attending early events may accelerate interns' ability and confidence in making conversation and developing relationships.

Importantly, the powerful influence of supervisor support in WIL (Smith et al. 2014) and micro/small business' difficulties in facilitating this due to time or lack of expertise (Kay et al. 2018) cannot be supplanted by the co-working environment. Interns need positive direct support from their supervisor; regular, constructive feedback; the opportunity to work alongside them; and a contingency plan for their absence. A potential strategy to manage this could be sharing interns across community businesses, giving students exposure to different areas of work and relieving time pressures on supervisors. Another is supplementing supervision with discipline academics giving support on task completion and feedback. This could extend to academics co-supervising multiple interns as a shared resource within the co-working space, further bolstered by coordinated peer support among co-working space interns. Irrespective of how support is structured and the need for independent and autonomous working, mentoring styles should challenge interns, not overwhelm them.

Being prepared for internships is always important, but smaller businesses are less able to carry individuals with significant training needs (Department of Industry 2014). Greater transparency on student capabilities at the internship matching stage, mandatory preinternship research on host organisations, and co-working space visits to familiarise students with the environment would benefit. Further, skill development training in networking and industry-specific skills is needed to boost confidence and interns' willingness to "hit-theground-running". The university assigning micro/small businesses with interns who are proactive and able to engage in events and networking opportunities, are flexible with their time, confident, and keen to pursue a challenge may benefit all. Finally, findings clearly highlighted co-working spaces' influence on professional identity development, providing rich opportunities for socialisation into appropriate conduct, familiarisation with different industries, and engaging with the spirit of entrepreneurship. Developing familiarity and connection with the profession is a critical, yet somewhat overlooked aspect of graduate employability (Jackson 2016).

\section{Conclusion}

The study makes three significant contributions to the field of education. First, it affirms the value of WIL for preparing HE students for future work, particularly in enhancing critical thinking and communication skills, fostering innovative behaviour, promoting work/life balance, and building confidence. Second, it identifies factors that influence enterprise 
capability development during WIL and highlights how smaller businesses and co-working spaces can offer distinct learning opportunities compared with traditional settings. Finally, it presents strategies for designing WIL to leverage the benefits of the co-working space and help alleviate challenges associated with WIL in micro/small businesses. This could optimise stakeholder benefits and enable more smaller businesses to participate in WIL, aligning with the national WIL strategy (Universities Australia et al. 2015).

The study's mixed-method and multi-stakeholder approach allows cautious generalisation of findings, understanding the context was a single HE institution, a small cohort of interns, and a single, albeit large, co-working space in Australia. The study is focused on micro/small businesses within co-working spaces, and it should be acknowledged that larger organisations also utilise these spaces, such as satellite offices. Extending the research to examine intern/ supervisor perceptions in disciplines beyond business could help HE better prepare students for evolving work arrangements. Exploring the impact of hybrid internship models, and how they may mitigate against challenges in the co-working and micro/small business environment, would advance knowledge and practice further.

Funding This work was supported by Spacecubed under Grant Agreement Number G1004419.

Data availability Not available.

Code availability Not available.

\section{Declarations}

Ethics approval The research was approved by the human ethics committee of the lead author's institution.

Consent to participate All participants provided appropriate consent to participate in the study.

Consent for publication All authors provide consent for publication.

Conflict of interest The authors declare no competing interests.

\section{References}

Australian Council of Learned Academies (2016). Skills and capabilities for Australian enterprise innovation. ACOLA.

Australian Government (2020). National priorities and industry linkage fund. Australian Government.

Australian Industry Group (2016). Response to the inquiry into innovation and creativity. AIG.

Bacigalupo, M., Kampylis, P., Punie, Y., \& Van den Brande, G. (2016). EntreComp: The entrepreneurship competence framework. European Union. https://doi.org/10.2791/593884

Billett, S. (2011). Curriculum and pedagogical bases for effectively integrating practice-based experience. Australian Learning and Teaching Council.

Bouncken, R., \& Reuschl, A. (2018). Coworking-spaces: How a phenomenon of the sharing economy builds a novel trend for the workplace and for entrepreneurship. Review of Managerial Science, 12(1), 317-334. https://doi.org/10.1007/s11846-016-0215-y

Bowles, M., Bowes, N., \& Wilson, P. (2019). Future-proof human capabilities. International Journal of Business and Social Science, 10(11), 18-29. https://doi.org/10.30845/ijbss.v10n9p2 
Bridgstock, R. (2019). Graduate employability 2.0. In J. Higgs, G. Crisp \& W. Letts (Eds.), Education for employability: The employability agenda (pp. 97-106). Brill.

Bridgstock, R., \& Tippett, N. (2019). Higher education and the future of graduate employability. Edward Elgar.

Cascio, W. (2019). Training trends: Macro, micro, and policy issues. Human Resource Management Review, 29, 284-297. https://doi.org/10.1016/j.hrmr.2017.11.001

Chikeleze, M., Johnson, I., \& Gibson, T. (2018). Using debate to teach critical thinking and communication skills to future leaders. Journal of Leadership Education, 17(2), 123-137. https://doi.org/10.12806/v17/i2/a4

Clarke, M. (2017). Rethinking graduate employability: The role of capital, individual attributes and context. Studies in Higher Education, 43(11), 1923-1937. https://doi.org/10.1080/03075079.2017.1294152

Clifton, N., Füzi, A., \& Loudon, G. (2019). Coworking in the digital economy. Futures, 102439. https://doi.org/ 10.1016/j.futures.2019.102439

Coworking Resources (2019). Global coworking growth study 2019. Author.

Deloitte (2019). The path to prosperity: Why the future of work is human. Deloitte.

Department of Industry (2014). Engaging employers in WIL: Current state and future priorities. PhillipsKPA.

Edwards, D., Perkins, K., Pearce, J., \& Hong, J. (2015). WIL in STEM in Australian universities. Australian Council for Educational Research.

Fishburners (2020). Internships. Author.

Foundation for Young Australians (2015). Unlimited potential: A data and information resource on young Australians. FYA.

Foundation for Young Australians (2016a). Enterprise skills and career education in schools. FYA.

Foundation for Young Australians (2016b). The new work mindset. FYA.

Fuzi, A. (2015). Co-working spaces for promoting entrepreneurship in sparse regions. Regional studies, regional science, 2(1), 462-469. https://doi.org/10.1080/21681376.2015.1072053

Gribble, C. (2014). Employment, work placements and WIL of international students in Australia. International Education Association of Australia.

Hajkowicz, S., Reeson, A., Rudd, L., Bratanova, A., Hodgers, L., Mason, C., \& Boughen, N. (2016). Tomorrow's digitally enabled workforce. CSIRO.

Hurrell, S. (2016). Rethinking the soft skills deficit blame game. Human relations, 69(3), 605-628. https://doi. org/10.1177/0018726715591636

Howard, J. (2016). Securing Australia's future - capabilities for Australian enterprise innovation. Australian Council of Learned Academies.

Jackson, D. (2015). Employability skill development in WIL: Barriers and best practice. Studies in higher education, 40(2), 350-367. https://doi.org/10.1080/03075079.2013.842221

Jackson, D. (2016). Re-conceptualising graduate employability: The construction of pre-professional identity in the higher education landscape of practice. Higher Education Research and Development, 35(5), 925-939. https://doi.org/10.1080/07294360.2016.1139551

Jackson, D. (2018). Evaluating the capabilities associated with professional identity: Comparing the perspectives of WIL students and their workplace supervisors. Vocations and Learning, 12(2), 245-266.

Jackson, D., \& Bridgstock, R. (2020). What actually works to enhance graduate employability? The relative value of curricular, co-curricular, and extra-curricular learning and paid work. Higher Education, 1-17. https://doi.org/10.1007/s10734-020-00570-x

Jackson, D., Riebe, L., Meek, S., Ogilvie, M., Kuilboer, A., Murphy, L., Collins, N., Lynch, M., \& Brock, M. (2020). Using an industry-aligned capabilities framework to effectively assess student performance in nonaccredited WIL contexts. Teaching in Higher Education. https://doi.org/10.1080/13562517.2020.1863348

Jackson, D., Rowbottom, D., Ferns, S., \& McLaren, D. (2017). Employer understanding of WIL and the challenges of engaging in WIL opportunities. Studies in Continuing Education, 39(1), 35-51. https://doi. org/10.1080/0158037x.2016.1228624

Kay, J., Ferns, S., Russell, L., \& Smith, J. (2018). Expanding WIL possibilities: Enhancing student employability through innovative WIL models. Australian Technology Network of Universities.

Khazanchi, S., Sprinkle, T., Masterson, S., \& Tong, N. (2018). A spatial model of work relationships. Academy of Management Review, 43(4), 590-609. https://doi.org/10.5465/amr.2016.0240

Kline, R. (1998). Principles and practice of SEM. Concordia University.

Kropp, J. (2019). Key takeaways from coworking Europe 2019. AllWorkSpace.

Kruger, J., \& Dunning, D. (1999). Unskilled and unaware of it: How difficulties in recognising one's incompetence lead to inflated self-assessments. Journal of Personality and Social Psychology, 77(6), 121-134. https://doi.org/10.1037/0022-3514.77.6.1121

Lydon J, Dyer D., \& Bradley, C. (2014). Compete to prosper: Improving Australia's global competitiveness. McKinsey.

Mahlberg, T. \& Riemer, K. (2017). Coworking spaces Australia: The new places where people work, businesses grow, and corporates connect. Sydney Business Insights. 
Merriam, S. (1995). What can you tell from an N of 1? PAACE Journal of Lifelong Learning, 4, 50-60.

Milligan, S., Luo, R., Hassim, E., \& Johnston, J. (2020). Future-proofing students. University of Melbourne.

National Association of Colleges and Employers (2018). Job outlook 2019. NACE.

OECD (2014).OECD CoreCompetency Framework. Office of Talent, OECD.

OECD. (2021). Enterprises by business size (indicator). OECD.

Office Hub (2019). The 2019 Australian coworking market report. Office Hub.

Pennington, A. \& Stanford, J. (2019). The future of work for Australian graduates. The Australia Institute.

Property Council of Australia (2018). The future is flexible. PCA.

Rae, D. (2007). Connecting enterprise and graduate employability. Education+ Training, 49(8/9), 605-619. https://doi.org/10.1108/00400910710834049

Sin, C., \& Neave, G. (2016). Employability deconstructed: Perceptions of Bologna stakeholders. Studies in Higher Education, 41(8), 1-16. https://doi.org/10.1080/03075079.2014.977859

Smith, C., Ferns, S., \& Russell, L. (2014). The impact of WIL on student work-readiness. Australian Government.

Smith, J., Ferns, S., Kay, J., Russell, L., Marcus, M., \& Wache, D. (2019). Enabling and evidencing enterprise and entrepreneurship through WIL. Australian Technology Network.

Sony, M., \& Naik, S. (2019). Key ingredients for evaluating Industry 4.0 readiness for organizations. Benchmarking: An International Journal, 27(7), 2213-2232. https://doi.org/10.1108/bij-09-2018-0284

Succi, C., \& Canovi, M. (2019). Soft skills to enhance graduate employability: Comparing students and employers' perceptions. Studies in Higher Education, 45(9), 1834-1847. https://doi.org/10.1080/ 03075079.2019.1585420

Thomas, D. (2006). A general inductive approach for analysing qualitative evaluation data. American Journal of Evaluation, 27(2), 237-246. https://doi.org/10.1177/1098214005283748

Tynjälä, P., Välimaa, J., \& Sarja, A. (2003). Pedagogical perspectives on the relationships between higher education and working life. Higher Education, 46(2), 147-166. https://doi.org/10.1023/A:1024761820500

Universities Australia. (2019). WIL in universities. Universities Australia.

Universities Australia, Business Council of Australia, ACCI, AIG, \& ACEN. (2015). National strategy on WIL in university education. Universities Australia.

Winchester-Seeto, T., \& Piggott, L. (2020). 'Workplace or workforce': What are we preparing students for? Journal of University Teaching \& Learning Practice, 17(4), 11-17.

World Economic Forum (2020). The future of jobs report. WEF.

Publisher's note Springer Nature remains neutral with regard to jurisdictional claims in published maps and institutional affiliations. 